\title{
أثث التغيرات الحالية فى قطاع الدواجن على إنتاج دجاج اللحم فى مصر
}

\author{
لاميس فوزى البهنسى \\ معهد بحوث الاقتصاد الزراعى
}

Received: Sep. 10,2017

Accepted: Sep. 14,2017

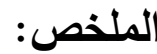

إستعهف البحث السى دراسة التغيرات الحالية قطاع لحم الدجاج خسال الفترة (2000-2015) وذلك من خسال دراسة الأهداف الفرعية التالية 1- دراسة الوضع الراهن للحم الدجاج في مصر.2 - نقدير معامل الأمن الغذائي للحم الدجاج. 3التتبؤ بالكتغيرات المؤثرة علي قطاع الدواجن في مصر. 4- تحليل الأثر الحالي للمتغبرات الخارجية علي الدتغيرات الداخلية.

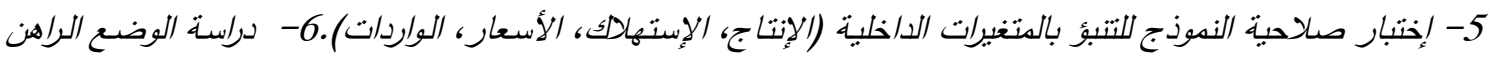

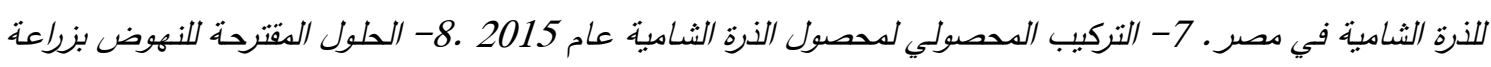

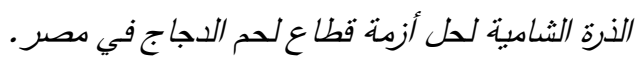
وقل توصل البحث لعدة نتأتج أهمها: (1) تفوق معدل ندو الاستهالاك المحلي عن الانتاج الدحلي فقد إزدات الواردات

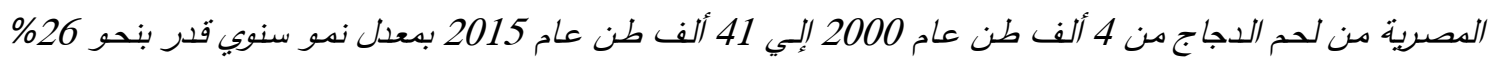
خلال فترة الدراسة .(2) معامل الأمن الغذائى للحم الدجاج بلغ حوالى 0.87 .و هو يكفي لأكثرمن ستة أثهر على الأقل

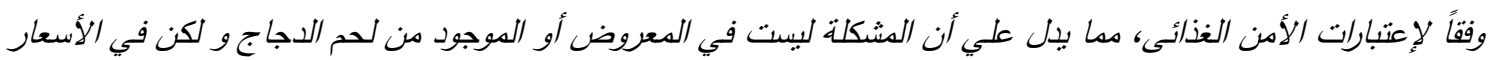

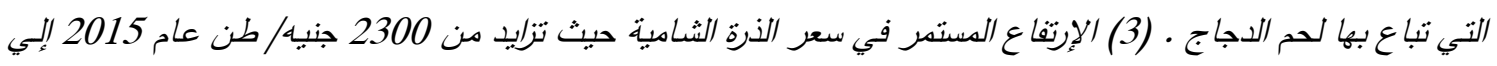

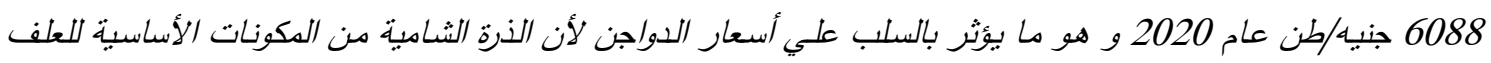

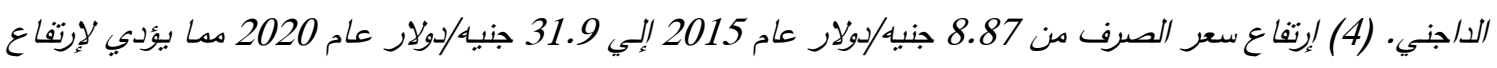

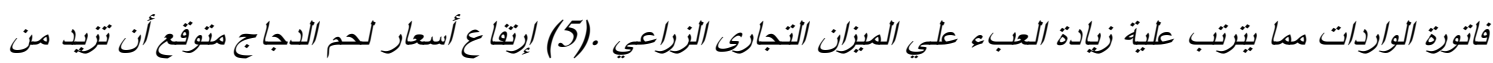

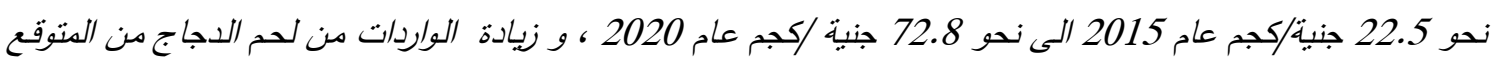

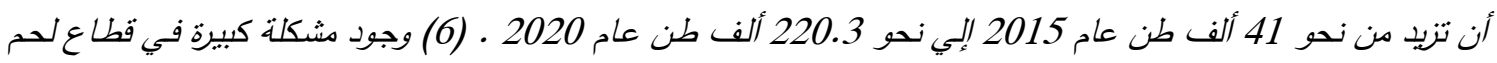

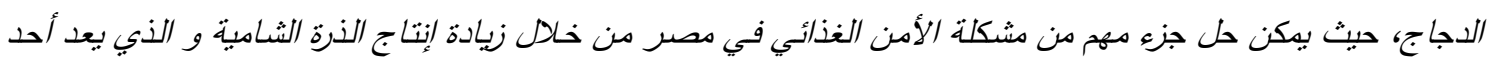

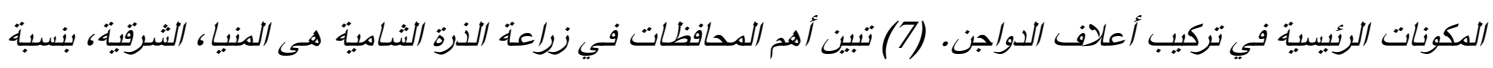
بلغت نحو 13.17\%، 11.88\%، 10.01\% 8.6 من إجمالي الدساحة الدنزرعة من محصول الذرة الشامية لكل منهم

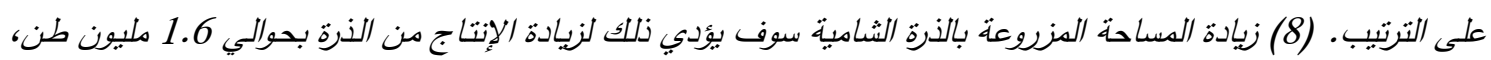

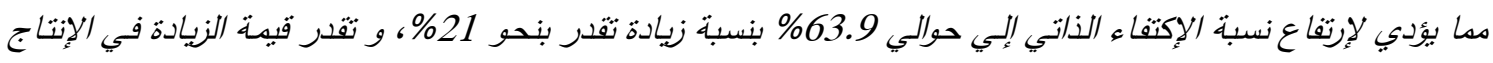

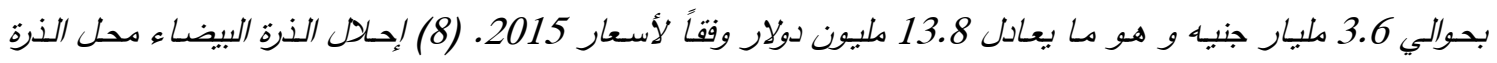

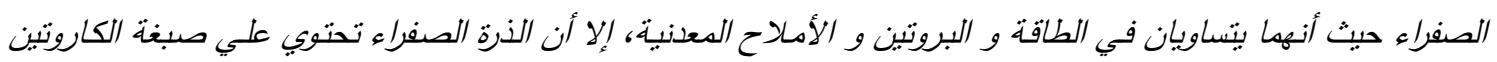

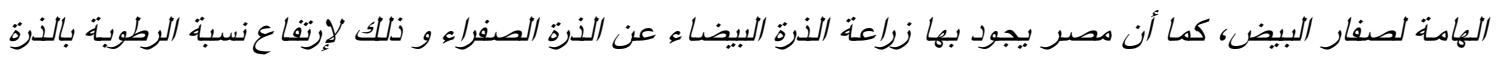

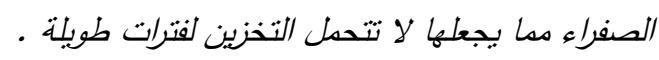


2015) وذلك من خـلال دراسـة الأهداف الفرعية التالية:

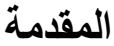

1- دراسـة الوضـع الراهن للحم الدجاج في مصـر . 2-

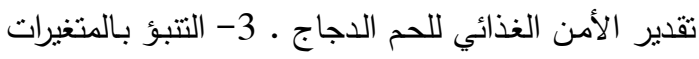

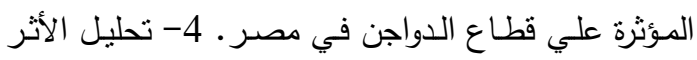
الحالي للمتغيرات الخارجية علي المتغيرات الداخلية. 5-

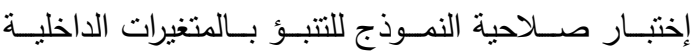

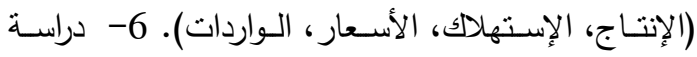

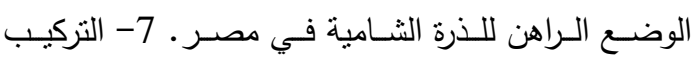
المحصــولي لمحصــول الـذرة الثــامية عـام 2015 .8الحلول المقترحة للنهوض بزراعة الذرة الثامية لحل أزمة

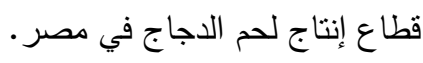

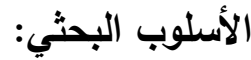

تم إستخدام الدنهج التحليلى الوصفي والكمي لتحقيق

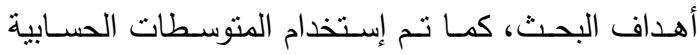
والنسب المئويـة ، واستخدام بعض المقاييس الإحصـائية

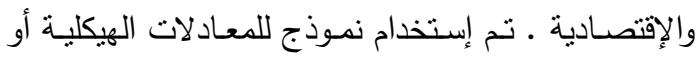

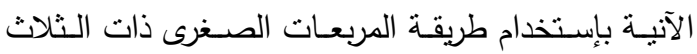

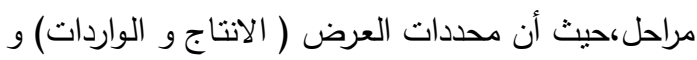

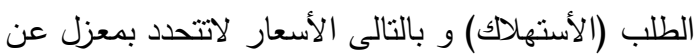

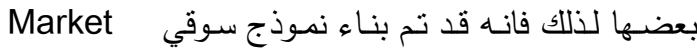
Model من ثم فقد نم تكوين نموذج اقتصادى قياسى لقطاع دجاج

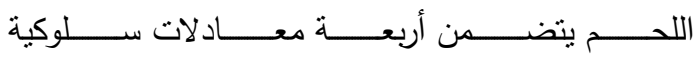
(هehavioral Equations (هيكلية) تعبر عن كل من الأنتاج و الأستهلاك و الأسعار و الواردات كالأتى:

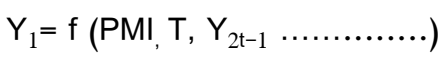

$Y_{2}=f\left(Y_{2 t-1}, P M I, I W, Y_{3} \ldots\right) \ldots \ldots . .(1)$

$Y_{3}=f\left(Y_{3 t-1}, P M, P M I \ldots \ldots \ldots . ..\right)$

$Y_{4}=f\left(Y_{3 t-1}, C P, P R \ldots . ..\right)$

ومن ثم فان النموذج ينكون من أربعة متغيرات داخلية تمثل ( الانتاج، الأسعار ،الواردات، الأستهلاك).

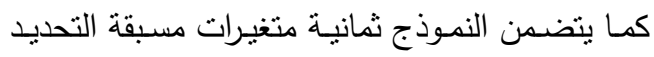
Predetermined Exogamous

تعتبر صناعة الدواجن في مصر من أهم الصناعات التي تسهم في توفير البروتين الحيواني و أصبح إنتاج

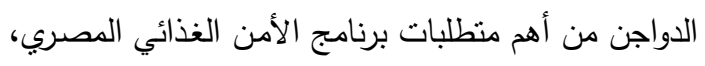

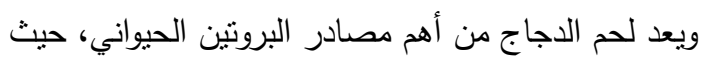

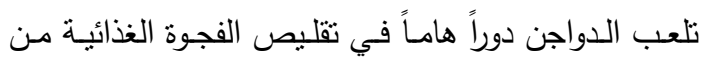

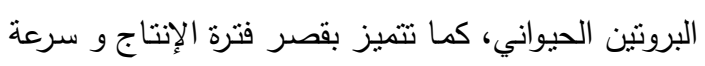

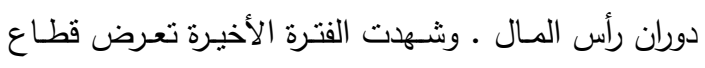

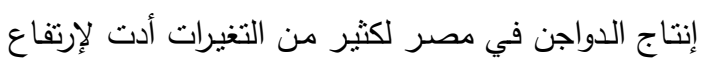

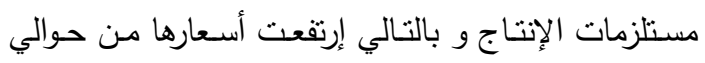
8.3 جنيـه/كجم عـام 2000 إلـي حـوالي 22.5 جنيـه /

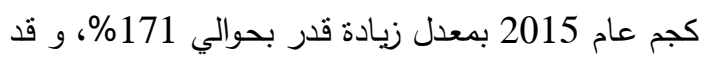
أرجعت الزيادة خلال تلك الفترة إلي عدم توافر الأعلاف و

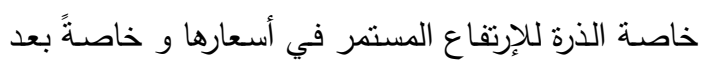
تحرير سعر الصرف مما يؤدي إلي زيادة فاتورة الواردات

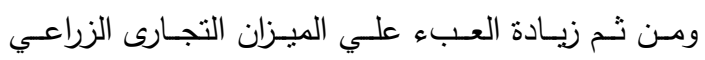
المصري.

\section{مشكلة البحث:}

بالرغم من أن مصر شهدت نطورات منباينة في إنتاج

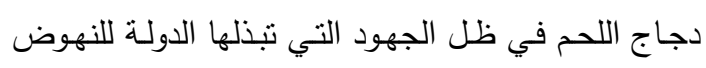

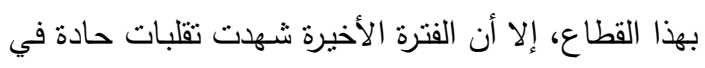
الأسعار نتيجـة الإرتفاع المستمر في مستلزمات الإنتاج خاصةً أسعار الأعلاف، فضـلاً عن تزايد معدلات الأنفاع النفوق

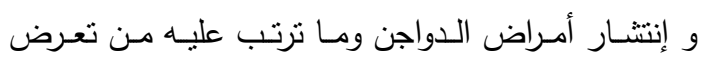

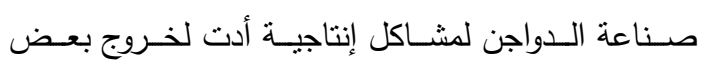

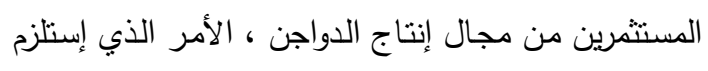

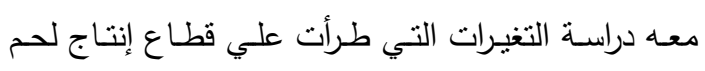

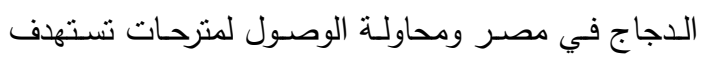
النهوض بالقطاع في ظل الوضع الراهن.

\section{الههف من البحث:}

إستهدف البحث بصفة رئيسية لدراسة التغيرات الحالية

قطاع إنتاج لحم الدجاج في مصرخلال الفترة (2000- 
حيث yt+1 قيمة المتغير الداخلى فى الفترة التالية و

النى تنكون من جزئين أساسيين

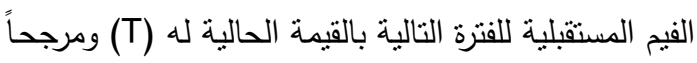

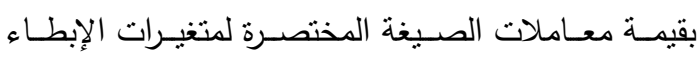
Lagged variables ، و و هذا الجزء يعبر عن العلاقة الإنة

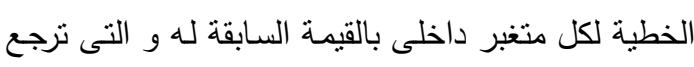

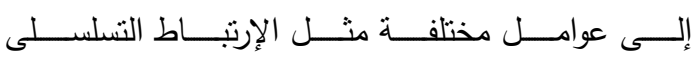
· (Intriligator.M,1978)

أما الجزء الثانى فهو

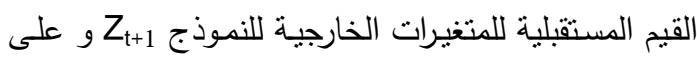
معاملات الصيغة المختصرة لهذه المتغيرات الخارجية ${ }^{\wedge}{ }^{\wedge}$

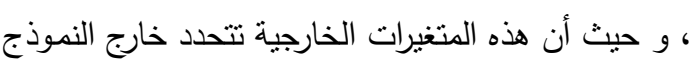

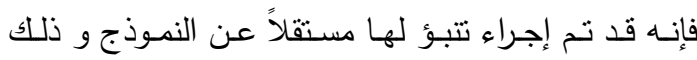

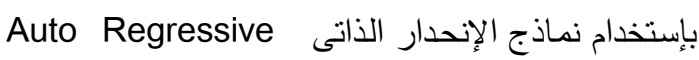
Models

$\mathrm{Cp}=\mathrm{f}\left(\mathrm{cp}_{\mathrm{t}-1}, \mathrm{t}\right)$

$\mathrm{Mpi}=\mathrm{f}\left(\mathrm{mpi}_{\mathrm{t}-1}, \mathrm{t}\right)$.

$M p=f\left(m p_{t-1}, t\right)$

$\mathrm{Iw}=\mathrm{f}\left(\mathrm{iw} \mathrm{w}_{\mathrm{t}-1}, \mathrm{t}\right)$

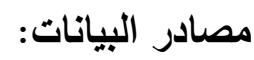

تم الاعتماد على البيانات الثانوية، التي تم الحصول عليها من وزارة الزراعة واستصلاح الأراضي، والجهاز

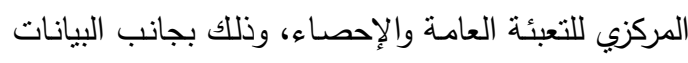

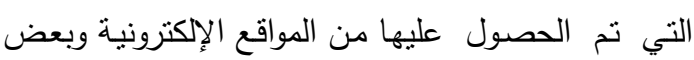
الدراسات والبحوث الاقتصادية المنعلقة بهذا المجال.

\section{النتائج البحثية و المناقشة :}

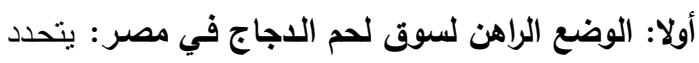

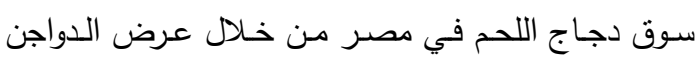

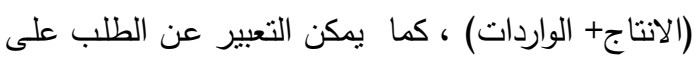

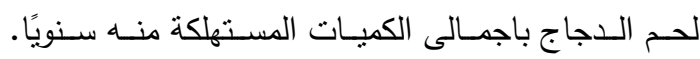

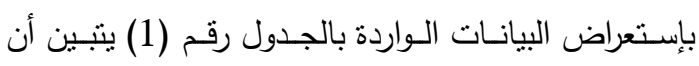
الإنتاج المحلي من لحم الدجاج قد تزايد من حوالي 548

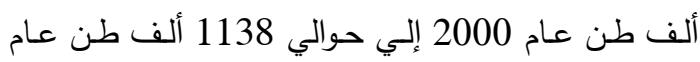
2015 بمعدل نمو سنوي قدر بنحو 2\%، في حين إزداد
خارجيـة وهـى سـعر اللحم الأحمر (PM) ،متغير الزمن (T)

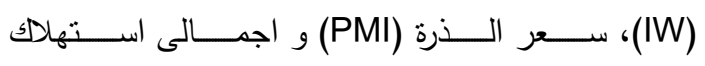
الدواجن(CP) و سعر الصرف(PR).و انثين من متغيرات

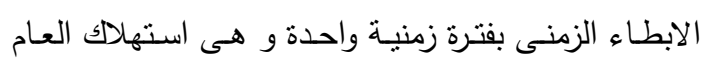

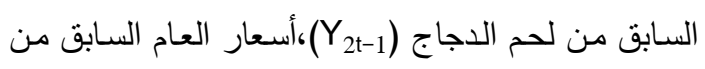

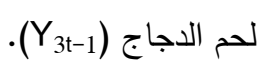

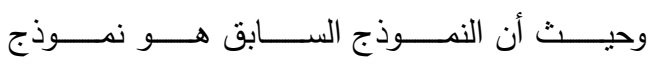
آنى Simultaneous تظهر فيه المتغيرات الداخلية فى

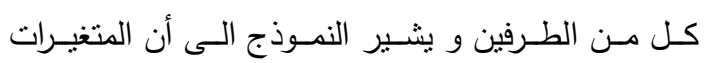

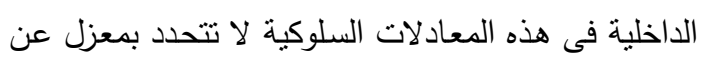

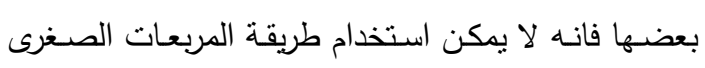

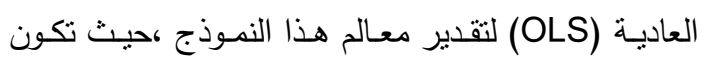
بعض المتغيرات المفسرة مرتنطة بحد الخطأ و بالتالى ينت الحصول على مقدرات متحيزة و غير منسقة ـ و بإختبار

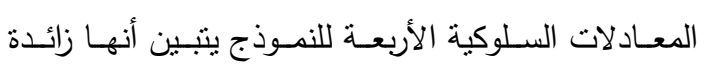
التمييز Over identified حيث أن عدد المتغيرات

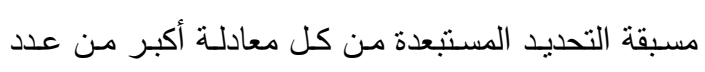

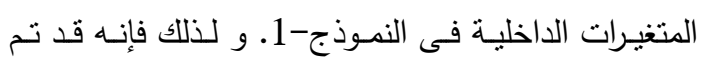

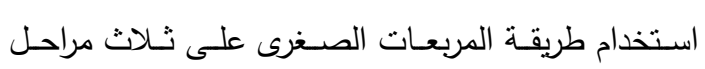

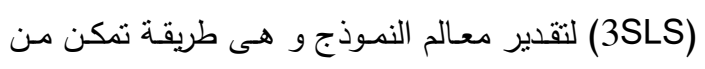

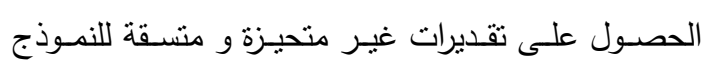
الآنى. وحيث أنسه لا يمكن إستخدام المعـادلات الهيكلية فى القى

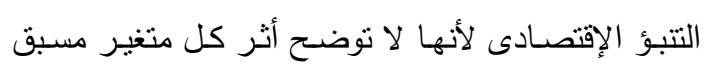

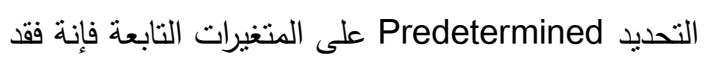
تم إثتقاق الصيغة المختصرة Reduced form و التى على التى توضـح هذا الأثر و من ثم يمكن التتبؤ بقيم المتغيرات الداخلية إستتاداً إلى معاملات الصيغة المختصرة المقدرة . و إستتاداً إلى الصيغة المختصرة فإنـة قد تم إجراء التتبؤ

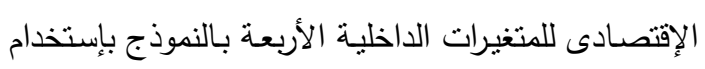

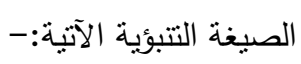

$\mathrm{Y}_{\mathrm{t}+1}=\mathrm{y}_{\mathrm{t}} \pi^{\wedge}{ }_{1}+\mathrm{Z}_{\mathrm{t}+1} \pi^{\wedge}{ }_{2}+\mu_{\mathrm{t}+1}$ 
الأمن الغذائي النسبي: ويقد به قدرة دولة ما أو مجموعة من الدول على توفير السلع والمواد الغذائية كلياً

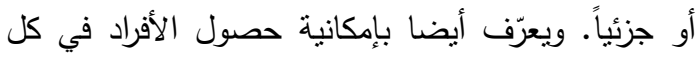
وقت على الغذاء الكافي لحياة حيوية وصحية بالثروط الثانية التالية: التوفر الدائم لأغذية آمنة ومغذية، إمكانية الحصول

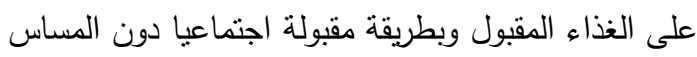

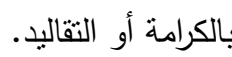

يمكن تقدير معامل الأمن الغذائى بإستخدام المعادلات الإقتصادية التالية

الاستهالاك المحلى اليومى = إجمالى الاستهلاك المحلى / 365

فترة كفاية الانتاج للاستهلاك = إجمالى الانتاج المحلى /

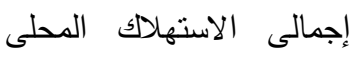

$$
\text { اليومىى }
$$

فترة تغطية الواردات للاستهلاك = كمية الواردات / إجمالى لئى الإدي

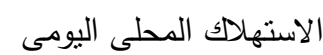

مجموع الفترتين= فترة كفاية الانتاج للاستهلاك+ فترة الانكي

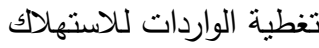

حجم المخزون الإستراتيجى = كجموع فترتى كفاية الانتاج ، تغطية الواردات

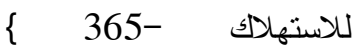

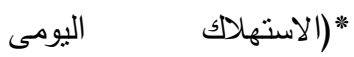

المحلى) - كمية الصادرات

معامل الأمن الغذائى = حجم المخزون الإستراتيجى|

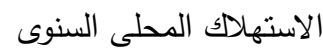

يتبين أن معامل الأمن الغذائى للحم الدجاج خلال

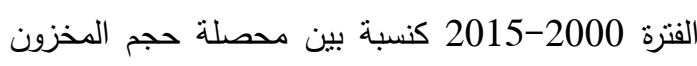

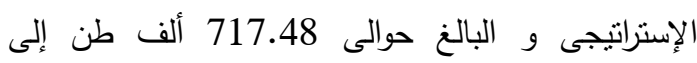
متوسط الإستهلاك السنوى و البالغ حوالى 821.5 ألف الف الفي

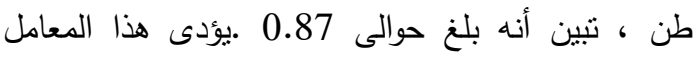

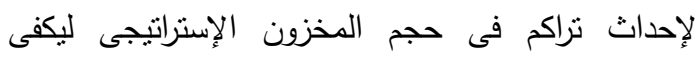
الإستهلاك المحلى لأكثرمن ستة أشهر على الأقل وفقاً

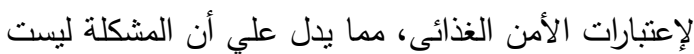

الاستهالك المحلي من لحم الدجاج من حوالي 548 ألف طن عام 2000 إلي حوالي 1176 ألف طن عام 2015

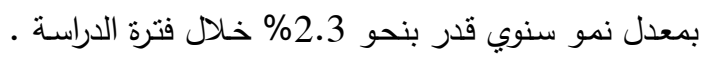
ونظراً لتفوق معدل نمو الاستهلالك المحلي عن الاتناج

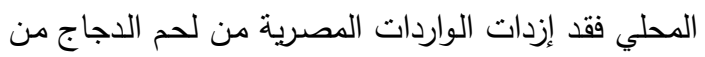
حوالي 4 ألف طن عام 2000 إلي حوالي 41 ألف طن لون

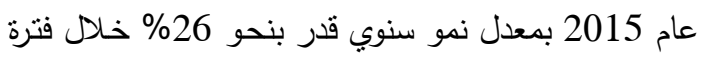
الدراسـة ـ بدراسـة الفجوة الغذائيـة لـاجاج اللحم تبين أنها أخذت تتراوح بين الإزدياد و العجز ، حيث تبين أن أدني

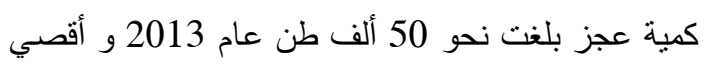
كمية عجز بلغت حوالي ألف طن عام 2004 ، بينما نبين

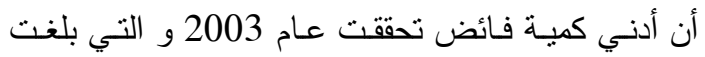
حوالي ألف طن و أقصي كمية فائض بلغت حوالي 41 ألف طن عام 2008. و قد برجع وجود فائض كبير إلي عزوف المستهلكين عن إستهلالك الدجاج نتيجة الإصـابة ولهابة

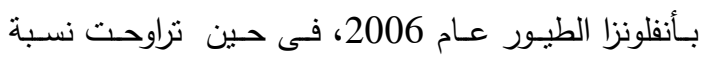

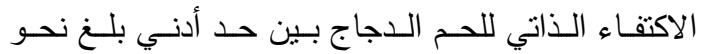
95.01\% عام 2013، وحد أقصي بلغ نحو 106.97\%

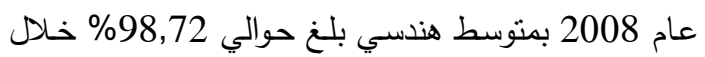

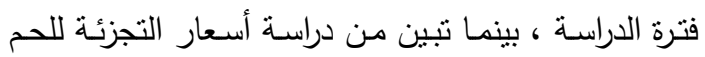

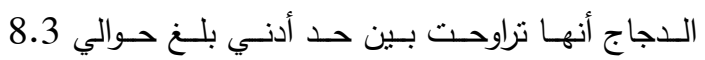

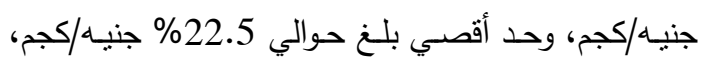
بمعدل نمو سنوي بلغ نحو 7.1\% وحئ

\section{معامل الأمن الغذائى للحم الاجاج:}

الأمن الغذائي: قدرة الدولة على إلثعار مواطنيها

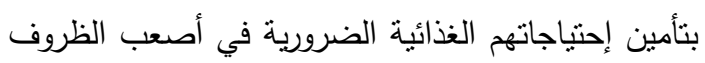

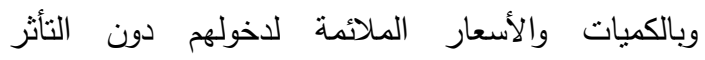
بالظروف المحيطة أو أي ظروف أخرى خارجية مما يبعث الاطمئنان لليهم، ويمكن التمييز بين مستوبين للأمن

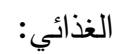

الأمن الغذائي المطلق: ويقصد به إنتاج الغذاء داخل

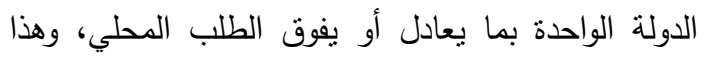
الدستوى مرادف للاكتفاء الذاتي الكامل ولذلك يطلق عليه بالأمن الغذائي الذاتي. 
قيم R ، و تبين من الأشكال رقم (1)، (2)، (3)، (4)

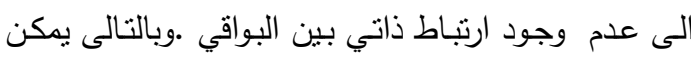

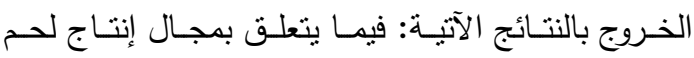

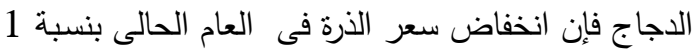

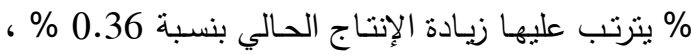

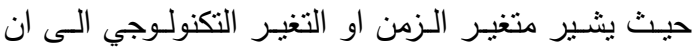

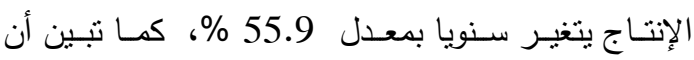

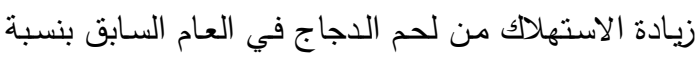

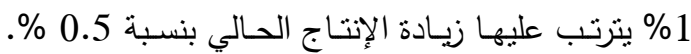
بدراسة الإستهلاك من لحم الدجاج فإن زيادة سعر الذرة بنسبة 1\% يترتب عليه نقص استهلاك لحم الدجاج بنسبة 0.45، وزيادة استهلاك العام السابق بنسبة 1\% بترتب عليـه زيـادة الاستهـلاك الحسالى بنسبة 0.63 \% وزيادة العادة انتاج العام الحالي بنسبة 1\% يتزتب عليه زيادة استهلاك الاك

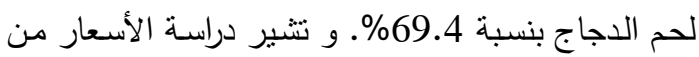

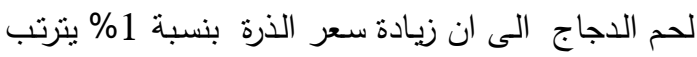
عليه زيادة سعر لحم الدجاج بنسبة 004\% و و زيادة سعر اللحوم الحمراء بنسبة 1\% يترتب عليه زيادة سعر لحم الدجاج بنسبة 0.09 \% .
في المعروض أو الموجود من لحم الدجاج و لكن في

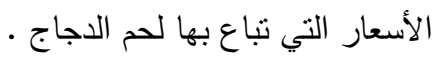

ثانيـا: التتبـؤ بـالمتغيرات المـؤئثرة علــي قطـــــ الدواجن في مصر:

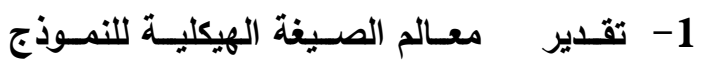

\section{: Structural Equations}

تثـير هـــه المعـادلات الـى التـأثنير الكمـي لتغيـر

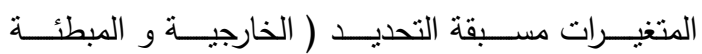
(Endogenous and Exogenous variables المتغيـرات الداخليــة. وبإنــتعراض جـدول رقــ(2) و المتغيرات المؤثرة علي قطاع الدواجن في مصر يتضح من

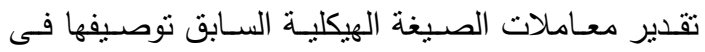

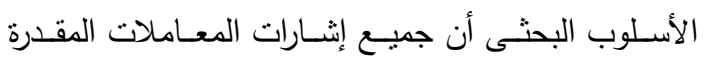
تتمشي مـع المنطـق الاقتصـادي ، كمـا ثبتـت معنويتهـا الاحصــائية علـى المسـتوي الاحتمـالي 0.01 ، 0.05

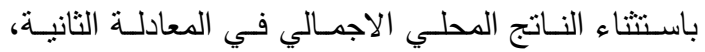

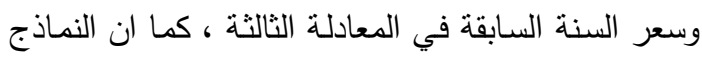

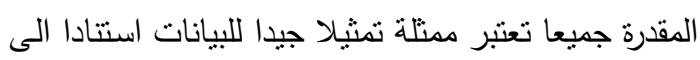

جدول رقم (2) : المعاملات المقدرة للصيغة الهيكلية

\begin{tabular}{|c|c|c|c|}
\hline المتغير التابع & المعاملات مسبقة التحديد & D w & $\mathbf{R}^{-2}$ \\
\hline الإنتاج & $\begin{aligned} Y_{1}=482.1+55.9 \mathrm{~T}-0.36 \mathrm{mpi}+0.51 \mathrm{y}_{2 \mathrm{t}-1} \\
(3.25)^{\circ} \quad(-3.05)^{\circ} \quad(3.24)^{*}\end{aligned}$ & 1.8 & 0.62 \\
\hline الاستهلاك & $\begin{array}{r}\mathrm{Y}_{2}=21.93+0.63 \mathrm{y}_{2 \mathrm{t}-1}-0.45 \mathrm{mpi}+0.01 \mathrm{iw}+69.4 \mathrm{Y}_{2} \\
(3.8)^{*} \quad(-2.8)^{*} \quad(0.98)^{* *} \quad(3.06)^{*}\end{array}$ & 1.7 & 0.42 \\
\hline الأسعار & $\begin{array}{r}Y_{3}=3.89+0.14 \mathrm{y}_{3 \mathrm{t}-1}+0.09 \mathrm{pm}+0.004 \mathrm{pmi} \\
(0.7) \quad(2.29)^{* *} \quad(3.22)^{*}\end{array}$ & 2.5 & 0.95 \\
\hline الواردات & $\begin{aligned} \mathrm{Y}_{4}=26.17+0.012 \mathrm{cp}+ & 4.43 \mathrm{y}_{4 \mathrm{t}-1}-4.91 \mathrm{iw} \\
(1.99)^{* *} & (9.6)^{*} \quad(-2.7)^{* * *}\end{aligned}$ & 1.9 & 0.88 \\
\hline
\end{tabular}

(0.05) * معنوى احصائيا عند

* معنوى احصائيا عند (0.01)

المصدر : جمعت و حسبت من : جدول رقم (1) 
باسـتخدام نمـاذج الانحـدار الذاتى الموصـفة فى الأسـلوب البحثى (النهـوذج رقم (3) و تظهر نتائج هذا التتبؤ فى الى

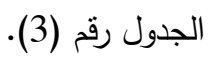

حيث أن زيادة اجمالى استهلاك الدواجن (cp) بنسبة

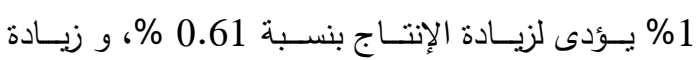
الاسـتهلاكك بنسـبة 0.88 \% و و زيــادة الأسـعار بنسـبة 0.001 \% و و زيادة الواردات بنسبة 0.02 \% ـ بـإجراء التتبؤ للمتغيرات الخارجيـة المؤثرة علي قطاع دجـاج اللحـم فـي مصـر و بإســتعراض البيانـات الـواردة بالجدول رقم (4) يتبين ما يلي:

الزيادة المستمرة في سعر الذرة الثـامية حيث زاد من حوالي 2300 جنيـ/ طن عام 2015 إلي حوالي 6088 جنيه/طن عام 2020 و هو ما يؤثر بالسلب علي أسعار الدواجن لأن الذرة الثـامية من المكونات الأساسبة للعلف الــداجني ، وإرتفــاع سـعر الصـرف مـن حـوالي 8.87 جنيه/دولار عام 2015 إلي حوالي 31.9 جنيه/دولار عام 2020 مما يؤدي لإرتفاع فاتورة الواردات مما يترتب علية زيادة العبء علي الميزان التجارى الزراعي المصري.
تشير الـواردات مـن لحم الـدجاج الـى ان زيـادة سـر العام السابق من لحم الدجاج بنسبة 1\% بيترتب عليه زيادة الواردات بنسبة 4.43\% و زيادة اجمالى استهلاك الدواجن بنسبة 1\% يترتب عليه زيادة الواردات بنسبة 012 \% \%

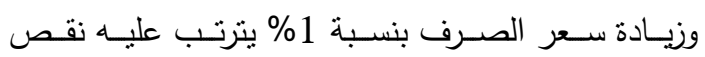

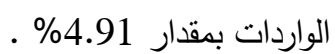

\section{2- تحليل الأثر الحـالى للمتغيـرات الخارجيـة ع.} Impact Analysis المتغيرات الداخلية لا يمكن معرفـة أثـر المتغيـرات الخارجيـة على كل متغير داخلى باستخدام الصيغة الهيكليـة ، و يتعذر ذلك لوجود المتغيرات الداخلية فى طرفى المعادلة و لذلك تبدأ من حسـاب الصـيغة المختصـرة Reduced form ، و و التى تبين أثر المتغيرات مسبقة التحديد على كل متغير داخلــى،و حيــث أن الصــيغة المختصــرة توضـــح أثـر المتغيرات مسبقة التحديد لكل متغير داخلى على حدة فانها أيضـا تصـلح لاجـراء التتبؤ المستقبلى استتادا للمعاملات

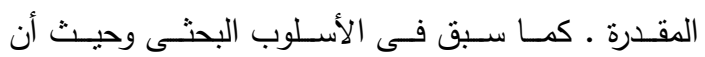
المتغيرات الخارجية تتحدد خارج النموذج فانه تم التتبؤ بها

جدول (3) :المعاملات المقدرة للصيغة المختصرة للنموذج

\begin{tabular}{|c|c|c|c|c|c|c|c|c|c|}
\hline \multirow{2}{*}{ المتغير التابع } & \multicolumn{2}{|c|}{ المتغيرات المبطأة } & \multicolumn{6}{|c|}{ المتغيرات الخارجية } & \multirow[t]{2}{*}{ الثابت } \\
\hline & $Y_{2 t-1}$ & $\mathbf{Y}_{3 \mathrm{t}-1}$ & Cp & Pmi & Pm & Iw & $\mathbf{T}$ & Pr & \\
\hline Y1 & -0.09 & 9.35 & 0.61 & 0.06 & 1.08 & 0.11 & -49.19 & 34.44 & -335.34 \\
\hline Y2 & -0.17 & 13.82 & 0.88 & 0.177 & 2.66 & 0.16 & -79.81 & 55.52 & -583.76 \\
\hline Y3 & -0.01 & -0.015 & 0.001 & 0.002 & 0.11 & 0.004 & 0.012 & 1.11 & 2.97 \\
\hline Y4 & -0.004 & 5.19 & 0.02 & 0.019 & 0.35 & -0.003 & -5.26 & -2.7 & -50.8 \\
\hline
\end{tabular}

المصدر : جمعت و حسبث من : جدول رقم (1) 
مخرجات برنامج E Veiws للكثف عن الارتباط الألتي لبواقي نموذج المعادلات الأنية المقدرة لانتاج لحم الدجاج

\begin{tabular}{|c|c|c|c|c|c|c|c|c|}
\hline Autocorre & ion & Partia & Correlation & & $A C$ & PAC & Q-Stat & Prob \\
\hline 1 & I & I & I & 1 & 0.126 & 0.126 & 0.3052 & 0.581 \\
\hline I & I & I & I & 2 & 0.187 & 0.173 & 1.0214 & 0.600 \\
\hline I & I & I & I & 3 & 0.003 & -0.040 & 1.0216 & 0.796 \\
\hline I & I & I & I & 4 & -0.143 & -0.180 & 1.5144 & 0.824 \\
\hline I $\square$ & 1 & 1 & 1 & 5 & -0.186 & -0.158 & 2.4223 & 0.788 \\
\hline $1 \square$ & I & I & I & 6 & -0.423 & -0.366 & 7.5811 & 0.270 \\
\hline $1 \sqsubset$ & I & I & I & 7 & -0.288 & -0.231 & 10.232 & 0.176 \\
\hline I & I & I & I & 8 & -0.021 & 0.126 & 10.249 & 0.248 \\
\hline I & I & I & I & $\mathbf{9}$ & - 0.006 & 0.059 & 10.250 & 0.331 \\
\hline I & I & $\mathbf{I}$ & 1 & 10 & - o.010 & -0.178 & 10.255 & 0.418 \\
\hline I & I & I & 중 & 11 & 0.086 & -0.129 & 10.685 & 0.470 \\
\hline 1 & 1 & I & I & 12 & 0.087 & -0.143 & 11.227 & 0.510 \\
\hline
\end{tabular}

مخرجات برنامج E Veiws للكثف عن الارتباط الذلتي لبواقي نموذج المعادلات الأنية المقدرة لاستهلاك لحم الدجاج

\begin{tabular}{|c|c|c|c|c|c|c|c|c|c|}
\hline \multicolumn{2}{|c|}{ Autocorrelation } & \multicolumn{3}{|c|}{ Partial Correlation } & \multicolumn{2}{|r|}{ AC } & \multirow{2}{*}{$\begin{array}{l}\text { PAC } \\
0.033\end{array}$} & \multirow{2}{*}{$\begin{array}{c}\text { Q-Stat } \\
0.0205\end{array}$} & \multirow{2}{*}{$\begin{array}{l}\text { Prob } \\
\text { 0.886 }\end{array}$} \\
\hline ' & 1 & I & & 1 & 1 & 0.033 & & & \\
\hline i & i & I & & I & 2 & -0.133 & -0.134 & 0.3858 & 0.825 \\
\hline ' & ' & I & & I & 3 & 0.052 & 0.063 & 0.4467 & 0.930 \\
\hline ' & ' & I & & I & 4 & 0.068 & 0.047 & 0.5589 & 0.968 \\
\hline ' & I & 1 & & I & 5 & -0.013 & $-\mathbf{0 . 0 0 3}$ & 0.5636 & 0.990 \\
\hline ㄷ & ' & ㄷ & & ' & 6 & -0.544 & -0.546 & 9.1014 & 0.168 \\
\hline $\mathrm{I}$ & I & $\mathrm{I}$ & & ' & 7 & -0.092 & -0.082 & 9.3751 & 0.227 \\
\hline ' & 1 & 1 & & ' & $\mathbf{8}$ & 0.096 & -0.042 & 9.7058 & 0.286 \\
\hline i & i & i & & i & $\mathbf{9}$ & -0.134 & -0.113 & 10.443 & 0.316 \\
\hline ' & ' & ' & & ' & 10 & -0.121 & -0.112 & 11.141 & 0.347 \\
\hline I & 1 & ' & & ' & 11 & 0.064 & 0.049 & 11.380 & 0.412 \\
\hline ' & ' & I & 맘 & ' & 12 & 0.190 & -0.171 & 13.975 & 0.302 \\
\hline
\end{tabular}

مخرجات برنامج E Veiws للكثف عن الارتباط الذلتي لبواقي نموذج المعادلات الأنية المقرة لأسعار لحم الاجاج

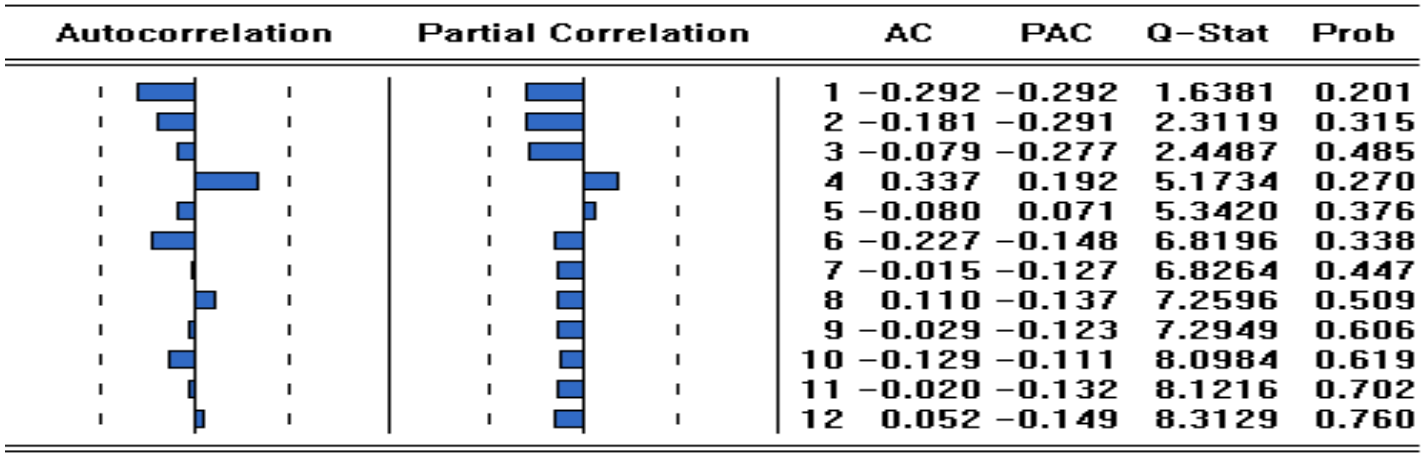

مخرجات برنامج E Veiws للكثف عن الارتباط الألتي لبواقي نموذج المعادلات الأنية المقدرة لواردات لحم الاجاج

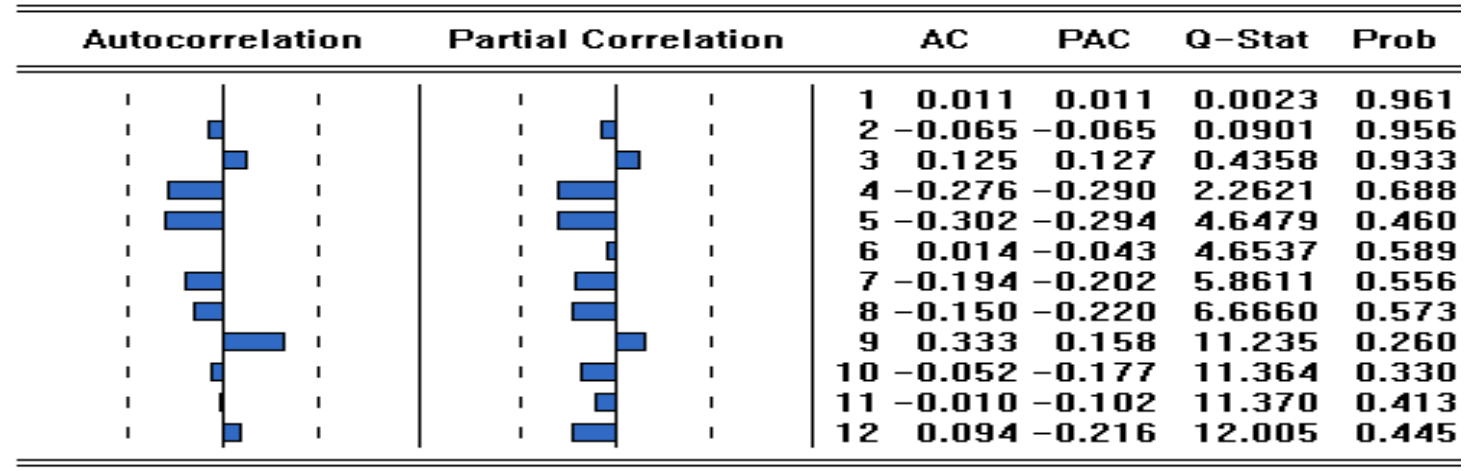


جدول رقم (4): القيم التنبوية للمتغيرات الخارجية بالنموذج باستخدام الاتحدار الذاتى

\begin{tabular}{|c|c|c|c|c|c|}
\hline سعر الصرف(Pr) & $\begin{array}{c}\text { الحقيقى(iw) } \\
\text { (iw) }\end{array}$ & الحمراء(mp) اللحوم & سعر الذرة & الدمالى استهلالك (cp) الداجن & لانينولت \\
\hline بالجنيه & مليون جنيه & جنيه / كجم & جنيه / كجم & ألف طن & \\
\hline 8.87 & 1795.5 & 79.5 & 2300 & 1495 & *2015 \\
\hline 13.07 & 2125.7 & 85.8 & 2772.7 & 2279 & 2016 \\
\hline 17.48 & 2960 & 99.6 & 3398.7 & 3129 & 2017 \\
\hline 22.1 & 3859 & 117.4 & 4159.9 & 3990 & 2018 \\
\hline 26.9 & 4822.7 & 139.1 & 5056.4 & 4880 & 2019 \\
\hline 31.9 & 5851.1 & 164.8 & 6088.1 & 5800 & 2020 \\
\hline
\end{tabular}

"تم وضع 2015 بهدف المقارنة

بالجدول رقم (4) و الى معاملات الصيغة المختصرة فقد

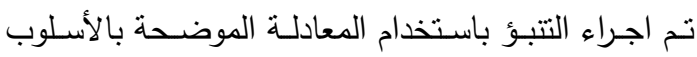
البحثى (نموذج رقم 2) ، و يوضح الجدول رقم (6) القيم التتبؤية للمتغيرات الداخلية في النموذج. و يتبين أن انتاج

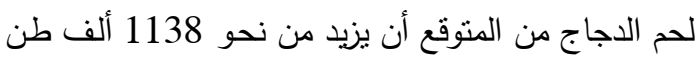

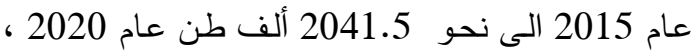

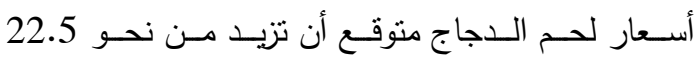
جنيـة/كجم عام 2015 الى نحو 72.8 جنيـة /كجم عام

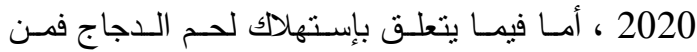
المتوقع أن يزيد من نحو 1176 ألف طن عام 2015 الى بـ

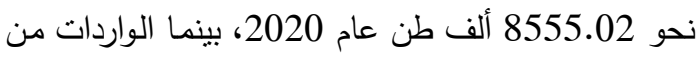

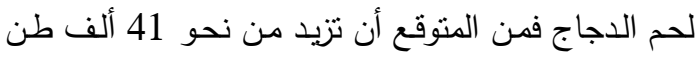
عام 2015 إلي نحو 220.3 ألف طن عام 2020 ـ
3- إختبار صلاحية النموذج للتنبؤ :-

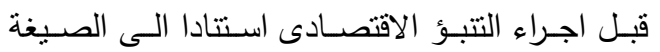

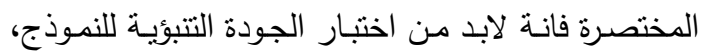
هذا وقد تم اختبار صـلاحية النمـوذج للتنبؤ مـن خـلال احصائية الجذر التربيعى لمربع خطأ التقدير (RMSE)

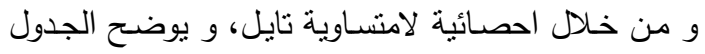
رقم (5MES) و ( R1) ) لكل من المغيرات الداخلية الأربعة بالنموذج • و يتبين من الجدول صلاحية النموذج للتنبؤ حيث تقترب لا منساوية تايل من الصفر و يدل ذلك على جودة النموذج التنبؤية . 4- التبؤ بالمتغيرات الداخلية للنموذج: و استنادا الى القيم التنبوية للتتغيرات الخارجية 
جدول رقم (5) :الكميات الاحصائية المحسوية لاختبار جودة النموذج

\begin{tabular}{|c|c|c|}
\hline \hline المتغيرات الداخلية & RMES & U1 \\
\hline \hline Y1 & 2.15 & 0.009 \\
\hline Y2 & 3.19 & 0.01 \\
\hline Y3 & 0.66 & 0.02 \\
\hline Y4 & 0.99 & 0.09 \\
\hline \hline
\end{tabular}

جدول رقم (6) : القيم التنبوئية للمتغيرات الداخلية بالنموذج

\begin{tabular}{|c|c|c|c|c|}
\hline الواردات & الأسعار & الاستهلاك & الإنتاج & السنوات \\
\hline 41 & 22.5 & 1176 & 1138 & *2015 \\
\hline 142.9 & 24.64 & 3353.4 & 2041.5 & 2016 \\
\hline 156.6 & 34.98 & 4531.4 & 2796.5 & 2017 \\
\hline 173.8 & 46.39 & 5791.6 & 3127.8 & 2018 \\
\hline 187.5 & 59.11 & 7331.9 & 4668.2 & 2019 \\
\hline 220.3 & 72.8 & 8555.02 & 5268.8 & 2020 \\
\hline
\end{tabular}

* ت تم وضع 2015 بهذف المقارنة

ثالثاً: الوضع الراهن لإنتاج الذرة في مصر: تنــنورد مصـر كميـات متزايـدة مـن الـــرة سـنوياً لإسـتخدامها في صـناعة الـواجن و التي تسـاهم بنسبة 50 من المكون العلفي للدواجن، ويرجع ذلك لعدم إقبال

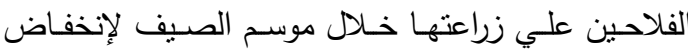
العائد منها مقارنةً بالمحاصيل الأخري.
مما سبق نستتتج وجود مشكلة كبيرة في قطاع لحم الـاجاج، حيث يمكن حل جزء مهم مـن مشكلة الأمسن الغذائي في مصر من خلال زيادة إنتاج الذرة الثنامية و

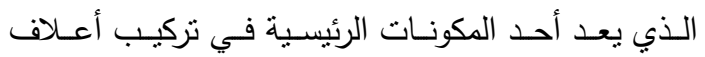
الدواجن • بل إن نوفير الذرة الثامية سوف ينعكس إيجابياً علي توفير كميات من القمح و الذي بستخدم في الريف المصـري كبديل علفي رخيص في الإنتاج الحيواني و الاجني سواء في صورته كحبوب أو كخبز. 
هندسي بلغ نحو 43.39 \% خلال فترة الدراسة، في حين

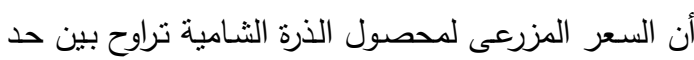

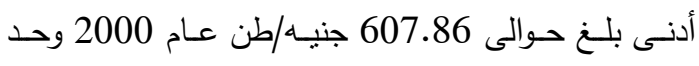
أقصى بلخ حوالى 2282 جنيد/طن عام 2015 بمنوسط

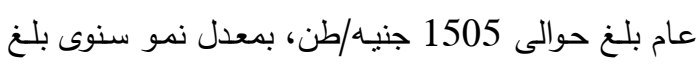

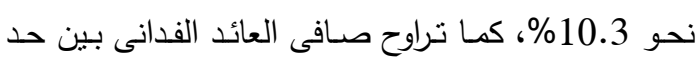

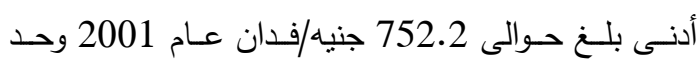
أقصى بلغ حوالى 3220 جنيه/فدان عام 2012 بمنوسط جلى

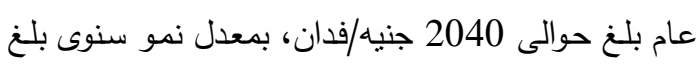
نحو 10\% خلال فترة الدراسة.

2- التجارة الخارجية لمحصول الذرة الثـامية خلال القترة (2000- 2015) :

بإسـتعراض البيانـات الـواردة بالجدول رقم(8) يتبين

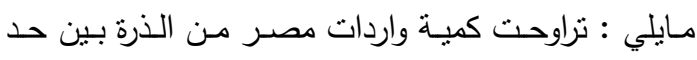

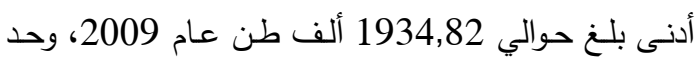
أقصسى بـــ حـوالي 7041,79 ألـف طـن عـام 2011 بمنوسط سنوي بلغ حوالي 4755 ألف طن، و لم تثبت المعنوية الاحصائية لكمية الواردات عند مسنويات المعنوية المألوفة (0.01 ، 0.05 ، 0.05 ). كما تبين أن قيمة واردات الذرة نراوحت بين حد أدنى

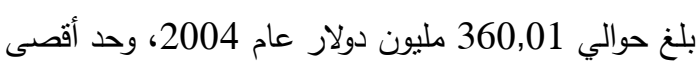
بلغ حوالي 2178,28 مليون دولار عام 2011 بمتوسط دولي سنوي بلغ حوالي1115 مليون دولار بمعدل سنوي بلغ نحو

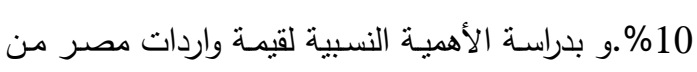

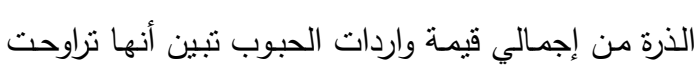

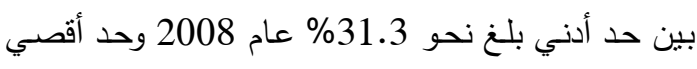
بلغ نحو 46.4 \% عام 2003 بمنوسط سنوي بلنغ نحو 39.08 \% خلال فنزة الدراسة.
1- المؤثـرات الإنتاجيـة و الإستهلاكية لمحصول الأرة الثامية خلال الفترة (2000-2015) بإستعراض البيانات الواردة بالجدول رقم (7) يتبين ما

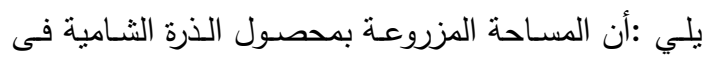
مصر تزاوحت بين حد أدنى بلغ حوالى 1623 ألف فدان عام 2000 وحد أقصى بلغ حوالى 2107 ألف فدان عام 2014بمتوسط عام بلغ حوالى 1810 ألف فدان خـلال

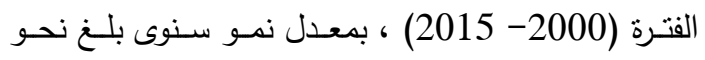
1.1\%، في حين تراوحت الإنتاجية الفدانية لمحصول الذرة الثامية بين حد أدنى بلغ حوالى 3.35 طن عام 2011

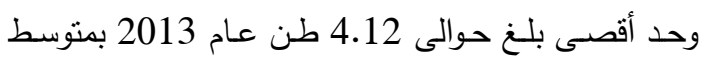
عام بلغ حوالى 3.54 طن، ولم تتبت المعنوية الإحصائية

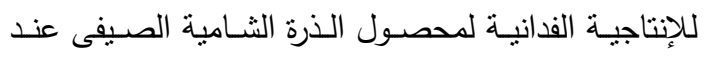
المستويات الاحتمالية المختلفة، تراوح إنتاج محصول الذرة

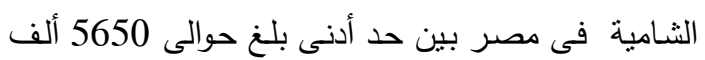
طن عام 2000 وحد أقصى بلغ حوالى لى 7245 ألف طن لن

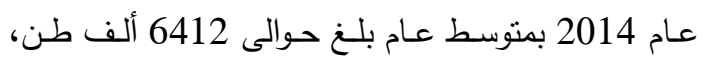
بمعدل نمو سنوى بلغ نحو 1.6\% ، كما تبين أن اجمالي الاسـتهلالك مـن الـــرة الثنـامية خـال الفتـرة (2000-

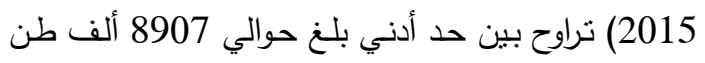
عام 2004 وحد أقصي بلغ حوالي 14074 ألف طن عام 2014 بمنوسط عام بلغ حوالى 11986 ألف طن، بمعدل نمو سنوى بلغ نحو 1.8\%، بينما تبين أن إستهلالك الذرة

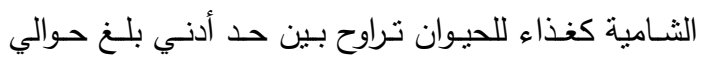

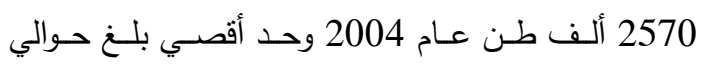
6989 ألف طن عـام 2014 بمتوسط عـام بلـغ حوالى وحسى

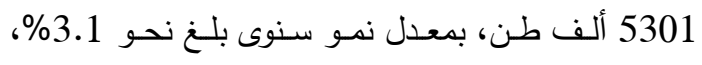

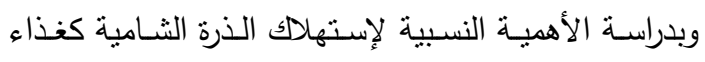

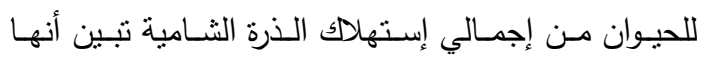
تراوحت بين حد أدني بلغ نحو 28.85\% عام 2004 و

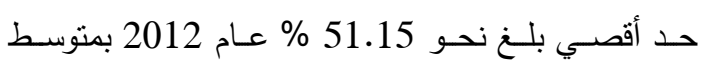


جدول رقم (7) : تطور المساحة والإنتاج و الاستهلاك و السعر المزرعي وصافي العائد لمحصول الأرة الثامية خلال

الفترة (2015-2000)

\begin{tabular}{|c|c|c|c|c|c|c|c|c|}
\hline صافئد & سعر المحصول & الألهبية & غذاء & الاستهلاك & الإنتاج & الإنتاجية & المساحة & \multirow[t]{2}{*}{ السنه } \\
\hline جنيه / طن & جنيه / طن & $\%$ & ألف طن & ألف طن & ألف طن & بالطن & ألف فدان & \\
\hline 762.9 & 607.86 & 47.35 & 5236 & 11058 & 5650 & 3.48 & 1623 & 2000 \\
\hline 752.2 & 612.86 & 44.04 & 4959 & 11259 & 6090 & 3.56 & 1710 & 2001 \\
\hline 824.4 & 629.29 & 42.44 & 4892 & 11526 & 5676 & 3.40 & 1668 & 2002 \\
\hline 855 & 692.86 & 39.58 & 4139 & 10457 & 5680 & 3.43 & 1658 & 2003 \\
\hline 1935 & 1035.71 & 28.85 & 2570 & 8907 & 5840 & 3.47 & 1685 & 2004 \\
\hline 1821 & 1078.57 & 41.46 & 4918 & 11862 & 6866 & 3.54 & 1940 & 2005 \\
\hline 1881 & 1578.58 & 36.77 & 4222 & 11482 & 6150 & 3.60 & 1708 & 2006 \\
\hline 3051 & 1414.29 & 42.92 & 4890 & 11392 & 6141 & 3.45 & 1782 & 2007 \\
\hline 1753 & 1378.57 & 45.46 & 5455 & 12000 & 6306 & 3.39 & 1860 & 2008 \\
\hline 1611 & 1871.43 & 44.88 & 5371 & 11967 & 6644 & 3.36 & 1978 & 2009 \\
\hline 2430 & 1928.57 & 43.35 & 5490 & 12663 & 7040 & 3.52 & 1998 & 2010 \\
\hline 2658 & 2164.29 & 49.66 & 6989 & 14074 & 5886 & 3.35 & 1759 & 2011 \\
\hline 3220 & 2242.86 & 51.15 & 6845 & 13381 & 7206 & 3.92 & 1839 & 2012 \\
\hline 3038 & 2264.29 & 48.75 & 6788 & 13925 & 7102 & 4.12 & 1724 & 2013 \\
\hline 2921 & 2300 & 46.91 & 5776 & 12313 & 7245 & 3.44 & 2107 & 2014 \\
\hline 3130 & 2282 & 46.49 & 6282 & 13513 & 7072 & 3.69 & 1916 & 2015 \\
\hline 2040 & 1505 & 43.76 & 5301 & 11986 & 6412 & 4 & 1810 & المتوسط \\
\hline$\% 10$ & $\% 10.3$ & - & $\% 3.1$ & $\% 1.8$ & $\% 1.6$ & N.S & $\% 1.1$ & معدل \\
\hline
\end{tabular}

المصدر:

وزارة الزراعة ،قطاع الثئون الاقتصادية، نثرة الميزان الغذائي ،الادارة المركزية للاقتصاد الزراعى، أعداد متفرقة

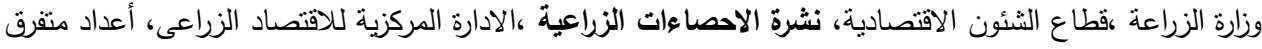


جدول رقم (8): تطور كمية وقيمة واردات مصر الذرة خلال الفترة (2000 - 2015)

\begin{tabular}{|c|c|c|c|c|c|c|}
\hline قاراردات & سعر الصرف & الأهية النسبية لقيمة & قيمة واردات الذرة & إجمالي قيمة & كمية الواردات & السنة \\
\hline مليار جنيه & جنيه/ دولار & $\%$ & مليون دولار & مليون & ألف طن & \\
\hline 1.93 & 3.48 & 44.35 & 555.02 & 1251.5 & 4958.24 & 2000 \\
\hline 2.20 & 3.98 & 45.26 & 552.71 & 1221.3 & 4797.09 & 2001 \\
\hline 2.67 & 4.52 & 41.96 & 591.43 & 1409.6 & 4720.21 & 2002 \\
\hline 3.15 & 5.97 & 46.41 & 527.5 & 1136.7 & 4038.33 & 2003 \\
\hline 2.24 & 6.21 & 32.94 & 360.01 & 1092.8 & 2406.55 & 2004 \\
\hline 3.96 & 5.79 & 42.13 & 684.3 & 1624.4 & 5018.3 & 2005 \\
\hline 3.11 & 5.75 & 35.80 & 541.69 & 1513.2 & 3757.97 & 2006 \\
\hline 5.28 & 5.64 & 36.92 & 936.71 & 2537.3 & 4466.72 & 2007 \\
\hline 5.38 & 5.54 & 31.30 & 971.53 & 3103.8 & 2538.39 & 2008 \\
\hline 4.63 & 5.56 & 34.24 & 833.45 & 2433.9 & 1934.82 & 2009 \\
\hline 7.18 & 5.66 & 36.40 & 1268.23 & 3483.9 & 5175.58 & 2010 \\
\hline 13.00 & 5.97 & 39.95 & 2178.28 & 5452.7 & 7041.79 & 2011 \\
\hline 11.94 & 6.1 & 36.59 & 1956.61 & 5347.1 & 6061.6 & 2012 \\
\hline 13.60 & 6.86 & 41.92 & 1982.47 & 4729.4 & 6121.36 & 2013 \\
\hline 13.77 & 7.09 & 38.45 & 1942.74 & 5052.2 & 6267.95 & 2014 \\
\hline 17.41 & 8.87 & 44.96 & 1962.61 & 4365.4 & 6779.47 & 2015 \\
\hline 6.97 & 5.81 & 39.35 & 1115.33 & 2859.70 & 4755.27 & المتوسط \\
\hline
\end{tabular}

comtrade.un.orghttps:II المصدر : جمعت و حسبت من الموقع الإكترونى 


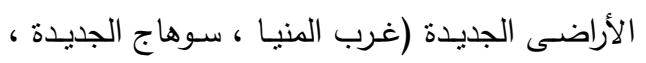

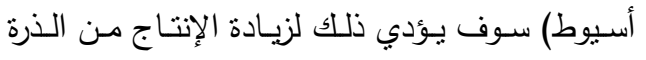

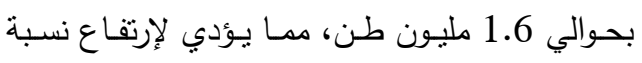

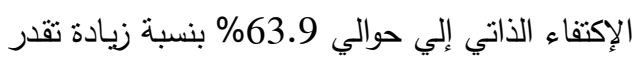
بنحو 21\%

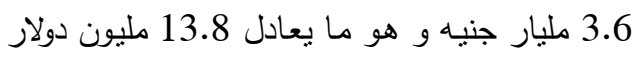

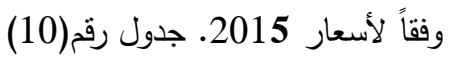
2-إحلال الذرة البيضـاء محل الذرة الصفراء حيث أنهـا

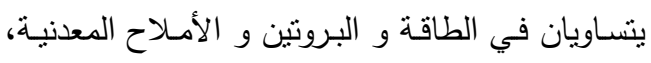

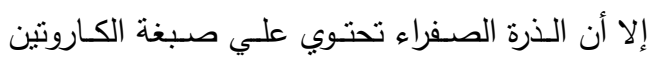

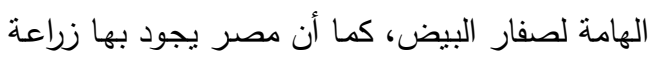

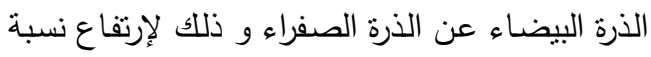

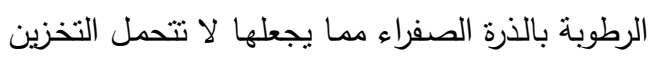
لفترات طويلة ـ ويتم ذلك من خلال إحلال كامل للذرة

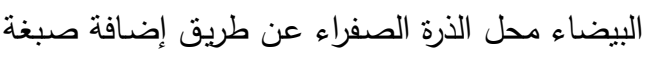

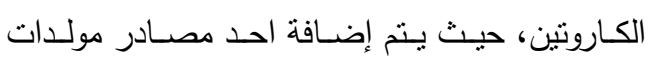
فيتامين(أ) الطبيعية التالية لمدة 12 أسبوع و منها

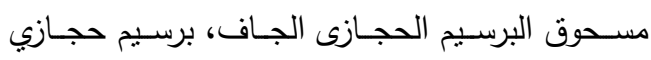

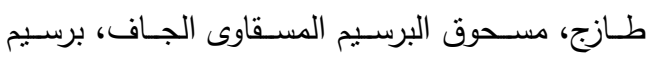

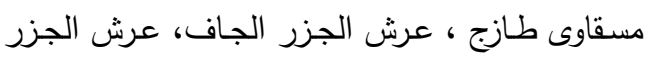

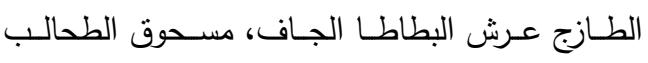

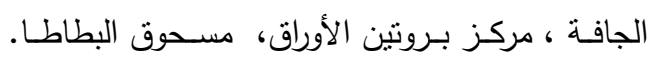
جدول رقم (10). نظراً لأن الأراضي المصرية لا يجود بها زراعة الذرة

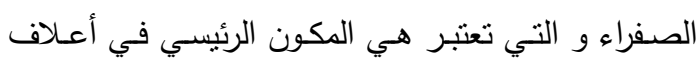

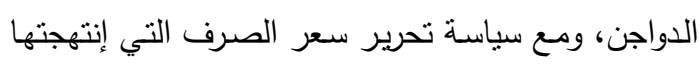

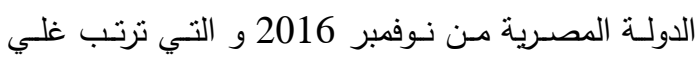
أثنارهـا وصـول سـعر الـولار إلـي حوالي 18 جنيـه، مدـا

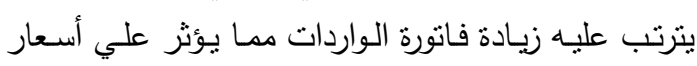
الدواجن لذلك يوصي البحث بتفعيل دور الزراعة التعاقدية

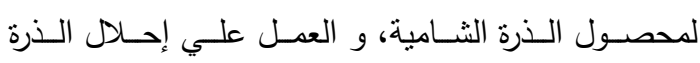

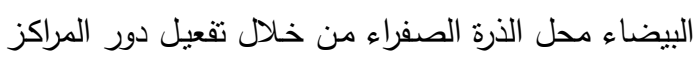

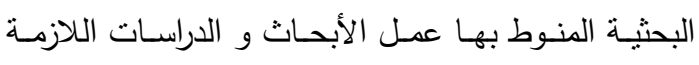

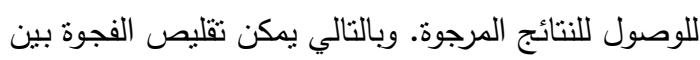

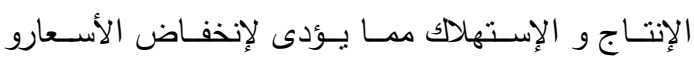

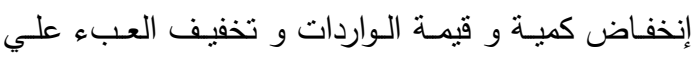
الميزان التجاري الزراعي الدصري، وتوفير العملة الصعبة.

\section{رابعـاً : التركيـب المحصــولي لمحصــول الــرة}

\section{الشامية عام 2015 : الشاتية}

بإستعراض البيانات الواردة بالجدول رقم (9) يتبين ما يلي:

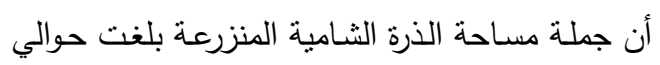

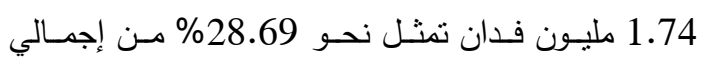
مساحة الحاصلات الصيفية والبالغة حوالي 6.08 مليون فدان، وجاءت محافظات الوجه البحري في المرتبة الأولي

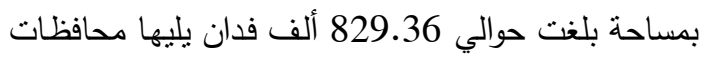
مصر الوسطى بمساحة بلغت حوالي 560.08 ألف فدان، ثم محافظات مصر العليا بمساحة بلغت حوالي 303.52 بالي

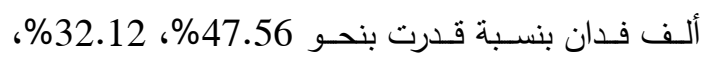

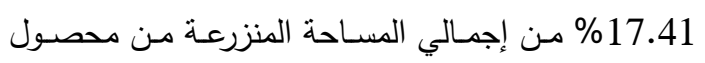
الذرة الثامية لكل منهم على الترتيب.

وقد تبين أهم المحافظات في زراعة الذرة الثشامية هى الثى المنيا، الثرقية، بني سويف و سوهاج بمساحة بلغت حوالي

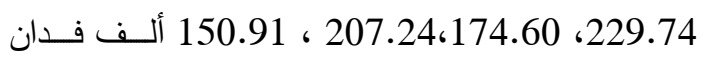

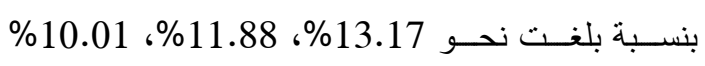
8.6 من إجمالي الدساحة المنزرعة من محصول الذرة الثامية لكل منهم على الترتيب.

\section{خامساً: الحلول المقترحة للنهوض بزراعة الذرة}

\section{الشامية لحل أزمة قطاع لحم الدجاج .}

في ضوء ما سبق ذكره عن محصول الذرة الثـامية

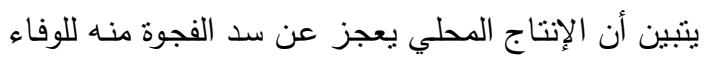

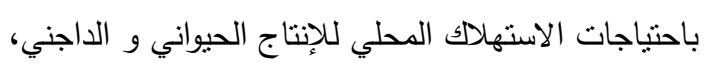

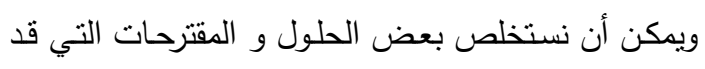

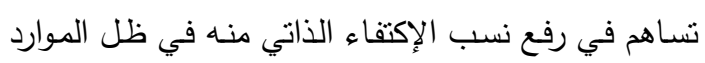

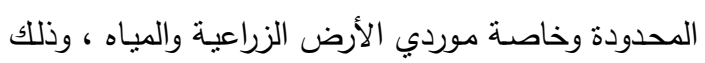

$$
\text { عن طريق ما يلي: }
$$

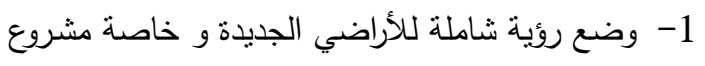

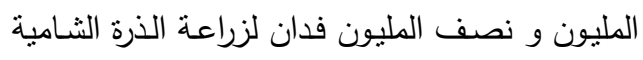

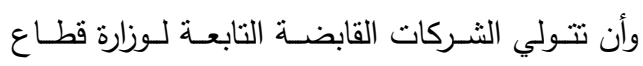

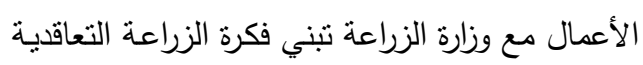

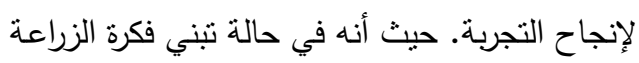

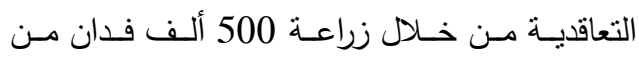




\begin{tabular}{|c|c|c|}
\hline المساحة المحصولية & الذرة الثامية & المحافظات \\
\hline 124.49 & 12.11 & الأسكندرية \\
\hline 797.27 & 165.11 & البحيرة \\
\hline 326.62 & 67.02 & الغربية \\
\hline 538.01 & 61.39 & كفر الشيخ \\
\hline 586.77 & 39.79 & الدقهلية \\
\hline 97.35 & 1.83 & دمياط \\
\hline 717.85 & 207.24 & الشرقية \\
\hline 97.81 & 27.36 & الاسماعيلية \\
\hline 55.37 & 10.28 & بور سعيد \\
\hline 13.53 & 4.39 & السويس \\
\hline 313.5 & 168.97 & المنوفية \\
\hline 146.9 & 63.81 & القليوبية \\
\hline 0.9 & 0.05 & القاهرة \\
\hline 3816.38 & 829.36 & جملة الوجه البحري \\
\hline 138.18 & 41.59 & الجيزة \\
\hline 232.12 & 174.6 & بني سوبف \\
\hline 294.7 & 114.15 & الفيوم \\
\hline 373.81 & 229.74 & المنيا \\
\hline 1038.8 & 560.08 & جملة مصر الوسطي \\
\hline 312.74 & 132.33 & أسيوط \\
\hline 288.83 & 150.91 & سوهاج \\
\hline 77.92 & 18.86 & قنا \\
\hline 34.36 & 0.01 & الأقصر \\
\hline 58.28 & 1.42 & أسوان \\
\hline 772.12 & 303.52 & جملة مصر العليا \\
\hline 5627.3 & 1692.96 & إجمالي داخل الوادي \\
\hline 30.37 & 0.24 & الوادي الجديد \\
\hline 43.51 & 6.7 & مطروح \\
\hline 0.33 & 0 & البحر الأحمر \\
\hline 13.26 & 0.15 & شمال سيناء \\
\hline 0.22 & 0.01 & جنوب سيناء \\
\hline 363.08 & 43.73 & النوبارية \\
\hline 450.77 & 50.83 & إجمالي خارج الوادي \\
\hline 6078.07 & 1743.78 & إجمالي \\
\hline
\end{tabular}

المصدر : وزارة الزراعة واستصـلاح الاراضـي ،قطاع الثـئون الاقتصادية ، نشـرة الاحصـاءات الزراعيـة - الجزء الثانى، القاهرة ، عام . 2015/2014 
جدول رقم (10): نتائج التوسع في زراعة الذرة الثامية

\begin{tabular}{|c|c|c|c|c|c|}
\hline \multicolumn{2}{|c|}{ قيمة المحصول } & الاكتفاء الذاتي & الانتاج & المساحة & \\
\hline مليون دولار & مليون جنيه & $\%$ & ألف طن & ألف فدان & \\
\hline 61.5 & 16138 & 52.3 & 7072 & 1916 & أراضي قديمة مزروعة \\
\hline 13.8 & 3559.9 & 11.5 & 1560 & 500 & أراضي جديدة مستصلحة \\
\hline 76.6 & 19698.2 & 63.9 & 8632 & 2416 & الإجمالي \\
\hline
\end{tabular}

"متوسط سعر محصول الذرة عام 2015 بلغ حوالي 2282 جنيه .

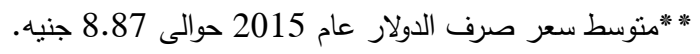

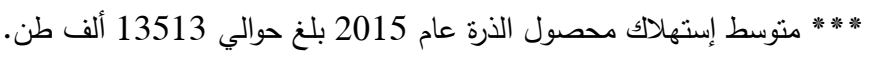

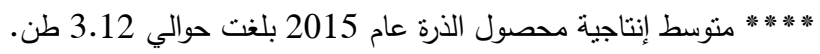

المصدر : جمعت و حسبت من بيانات جدول رقم (7)

4- Pindyck .and Rubinfeld, D.Econometric Models and Economic forecasts, McGraw-Hill Inc. New York, 1981.

5- Zellner, A.and Theil, H. Three stages Least Squares .Simultaneous Estionation of simultaneous Equations, Econometric, 1962.

6- Spyros, $M$ and Steven, $c$.forecasting Methods and Application, John Will \&Sons, New York, 1978.

7- El-Husseiny, O.; Sohir Arafa; Zeba AbdelMotagally and G. El-Mallah (2000). Response of layer performance to dietary natural pro-vitamin (a) sources. Egypt. Poult. Sci. Vol 20 (IV) Dec. 2000 (703719) (14) Davies, A.W. (1952). Nature PP $70: 849$

8-Intriligator.M, Econometric Models Techniques, and Application, PrenticeHallinc.New York. (1978).

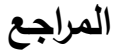

$$
\begin{aligned}
& \text { 1- جـادل المـلاح - نـــوذج اقتصـادى للتتبؤ بـالمتغيرات }
\end{aligned}
$$

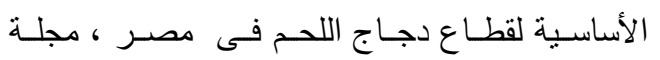

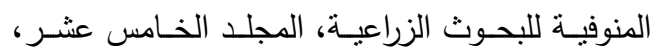

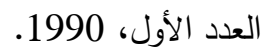

$$
\begin{aligned}
& \text { 2- وزارة الزراعــة ،قطــــاع الثـــئون الاقتصــادية، نشــرة }
\end{aligned}
$$

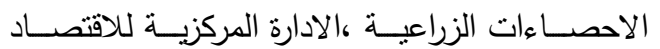

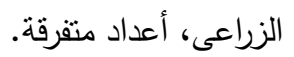

$$
\begin{aligned}
& \text { 3- وزارة الزراعة ،قطاع الثئون الاقتصادية، نشرة الميزان }
\end{aligned}
$$

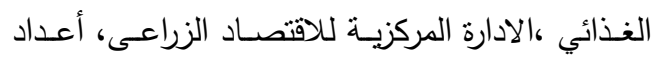

$$
\begin{aligned}
& \text { متفرقة }
\end{aligned}
$$




\title{
THE IMPACT OF THE CURRENT CHANGES IN THE POULTRY SECTOR ON THE PRODUCTION OF CHICKEN MEAT IN EGYPT
}

\author{
Lamis F. El-Bahnasy \\ Researcher in Agricultural Economics Research Institute
}

\begin{abstract}
The main objectives of this research to study the current changes in the chicken meat sector during the period (2000-2015) by studying the following sub-objectives: 1. studying the current status of poultry meat in Egypt. 2. Estimating the food security parameters of poultry meat. 3- Predicting the variables affecting the poultry sector in Egypt. 4 - Analysis of the current impact of external variables on internal variables. 5. Test the validity of the model to predict the internal variables (production, consumption, prices, and imports). 6. Study the current status of maize in Egypt. 7- The crop structure of the maize crop in 2015. 8- The proposed solutions to promote maize cultivation to solve the chicken meat crisis in Egypt. The research reached several results, the most important: (1) the growth rate of domestic consumption exceeded domestic production. Egyptian imports of chicken meat increased from 4 thousand tons in 2000 to 41 thousand tons in 2015 with an annual growth rate of $26 \%$ during the study period. About 0.87. It is enough for at least six months according to food security considerations, indicating that the problem is not in the supply or availability of chicken meat but at the prices at which chicken meat is sold. (3) The continuous rise in the price of maize, which increased from 2300 pounds / ton in 2015 to 6088 pounds / ton in 2020, which affects negatively on the prices of poultry because maize is one of the basic components of poultry feed. (4) The increase in the exchange rate from LE 8.87 / USD in 2015 to LE 31.9 / USD in 2020 , leading to an increase in the import bill, resulting in an increase in the burden on the agricultural trade balance. (5) The price of chicken meat is expected to increase from about 22.5 pounds / kg in 2015 to about 72.8 pounds / kg in 2020, and the increase in imports of chicken meat is expected to increase from about 41 thousand tons in 2015 to about 220.3 thousand tons In 2020. (6) The presence of a major problem in the chicken meat sector, where an important part of the problem of food security in Egypt can be solved by increasing the production of maize, which is one of the main components in the composition of poultry feed. (8) The increase in maize cultivated area will increase the production of maize by about 1.6 million tons, which will lead to an increase in maize production by about $13.17 \%, 11.88 \%, 10.01 \%$ Leading to a high self-sufficiency rate of $63.9 \%$ with an increase of about $21 \%$ C) about 3.6 billion pounds, equivalent to 13.8 million dollars according to the prices of 2015. (8) Substituting white maize substitutes where they are equal in energy, protein and mineral salts, but yellow maize contains the important carotene color of egg yolks, and Egypt has the advantage of growing maize for maize, because of the high humidity of yellow corn, which makes it not bear storage for long periods.
\end{abstract}

Key words: Poultry sector, Egypt, food security 